\title{
A case-control study of end-of-life treatment preferences and costs following advance care planning for adults with end stage kidney disease.
}

Running title: Advance care planning in ESKD

\section{Authors full name and highest degree:}

Marcus Sellars, BBSc, PGDipPsych ${ }^{1,2}$, Rachael L. Morton, $\mathrm{PhD}^{3}$, Josephine M. Clayton, MBBS, FRACP, $\mathrm{PhD}^{1,4}$, Allison Tong, $\mathrm{PhD}^{5,6}$, Daveena Mawren, BSc, $\mathrm{MA}^{2^{*}}$, William Silvester, MBBS, FRACP, FCICM ${ }^{2}$, David Power, MBBS, MD, $\mathrm{PhD}^{7}$, Ronald Ma, $\mathrm{PhD}^{8}$, , Karen M. Detering, MBBS, FRACP, MH Ethics ${ }^{2,19}$

\section{Institution of each author}

${ }^{1}$ Kolling Institute, Northern Clinical School, Faculty of Medicine, The University of Sydney, Australia;

${ }^{2}$ Advance Care Planning Australia, Austin Health, Melbourne, Australia;

${ }^{3}$ NHMRC Clinical Trials Centre, The University of Sydney;

${ }^{4}$ HammondCare Palliative \& Supportive Care Service, Greenwich Hospital, Sydney, Australia;

${ }^{5}$ Sydney School of Public Health, The University of Sydney, Australia;

${ }^{6}$ Centre for Kidney Research, The Children's Hospital at Westmead, NSW, Australia;

${ }^{7}$ Department of Nephrology, Austin Health, Melbourne, Australia;

${ }^{8}$ Clinical Costing, Austin Health, Melbourne, Australia;

This is the author manuscript accepted for publication and has undergone full peer review but has not been through the copyediting, typesetting, pagination and proofreading process, which may lead to differences between this version and the Version of Record. Please cite this article as doi: $10.1111 /$ nep. 13230

This article is protected by copyright. All rights reserved. 
${ }^{9}$ Faculty of Medicine, Dentistry and Health Sciences, Melbourne University, Parkville Vic 3010. Australia

* Centre for Forensic Behavioural Science, Forensicare and Swinburne University of Technology, Melbourne, Australia;

\section{Corresponding author}

Marcus Sellars, Research Fellow and PhD candidate, Advance Care Planning Australia, Austin Health, PO Box 5555, Heidelberg, Victoria 3084, Australia. Email: marcus.sellars@austin.org.au; p: (03) 94966755.

Word count (Abstract): 216

Word count (Body): 2,859

This article is protected by copyright. All rights reserved. 


\begin{abstract}
Aim: To examine the efficacy of advance care planning (ACP) to improve the likelihood that end-stage kidney disease (ESKD) patient's preferences will be known and adhered to at end-of-life.

Methods: A case-control study of a nurse-led ACP program in adults with ESKD from a major tertiary hospital. The primary outcome was the proportion of patients whose preferences were known (by substitute decision maker and/or clinicians) and adhered to by their treating doctors. Secondary measures were health system resource use and costs (\$AUD) for a nurse-led ACP intervention in the last 12-months of life. Results: In total, 57 cases (38 men, mean age 73.8 years) and 57 historical controls (38 men, mean age 74.0 years) were included. Cases $(38 / 57,67 \%)$ were significantly more likely than controls $(15 / 57,26 \%)$ to have their preferences known and adhered to by their treating doctor at end-of-life $(\mathrm{p}<0.001)$. Cases $(33 / 40,83 \%)$ were also significantly more likely to withdraw from dialysis in accordance with their preferences than controls $(11 / 33,33 \%)(\mathrm{p}<0.001)$. For cases, the average hospital costs in the last 12 months of life was AUD \$99,077 $(\mathrm{SD}=\$ 71,002)$ per patient. The total cost of the ACP program in 2010/11 was AUD \$26,821.
\end{abstract}

This article is protected by copyright. All rights reserved. 
Conclusion: ACP was associated with improvements in end-of-life care preferences known and adhered to for people with ESKD.

Keywords: advance care planning; chronic kidney disease; conservative care; costeffectiveness; nephrology.

This article is protected by copyright. All rights reserved. 


\section{Introduction}

Advance care planning (ACP) aims to empower patients, with the support of their caregivers, to consider and communicate their current and future treatment goals in the context of their own preferences and values. Yet ACP is estimated to occur with only $6-49 \%{ }^{1-5}$ of people with chronic kidney disease (CKD) internationally.

In the context of end-stage kidney disease (ESKD), ACP improves decision-making confidence among caregivers and congruence between patients with CKD and their caregivers. ${ }^{6,7}$ While there is a need to examine whether ACP improves the likelihood that CKD patient's treatment preferences will be known and adhered to at end-of-life; only one study has reported end-of-life outcomes following ACP. ${ }^{8}$ In addition, there is little information on the health system resources involved in ACP and the costs to providing this service to a population with end-stage kidney disease. ${ }^{9}$ We hypothesized that coordinated ACP would improve adherence to patient preferences at end-of-life.

We report the results of a retrospective analysis of ESKD decedents using medical records of renal patients and the hospital registry at a major tertiary hospital with a dedicated nurse-led ACP service to determine (1) adherence between ESKD patient's treatment preferences and end-of-life care; (2) the health system resources involved in a dedicated nurse-led ACP service in ESKD; and (3) the hospital resource use and costs in the last 12-months of life for adults on dialysis.

This article is protected by copyright. All rights reserved. 


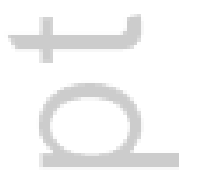

This article is protected by copyright. All rights reserved. 


\section{Materials and Methods}

\section{Study design}

Using a retrospective case-control design, we collected retrospective data from patient medical records from Austin Health's referral attendance details system, which records electronic alerts, ACP referrals and health system resource use including nurse consultations, hospital admissions, procedures and allied health outpatient appointments. Ethics approval was obtained from Austin Health's Human Research Ethics Committee (reference number: LNR/17/Austin/555). Study reporting is based on the STROBE statement for case-control studies. ${ }^{10}$

\section{Setting}

This project was initiated by the Advance Care Planning and Nephrology departments to assess the impact of ACP on ESKD patient's end-of-life treatment outcomes at Austin Health, Melbourne, Australia. Since March 2010, a trained ACP facilitator was employed to undertake ACP with people with CKD. Prior to this, there was no such structured approach to ACP within the Nephrology department. The program was jointly funded by the Department of Health Victoria under a specific ACP program implementation grant, and the department of nephrology at Austin Health.

This article is protected by copyright. All rights reserved. 
The ACP program provides a coordinated approach to ACP whereby the ACP trained dialysis nurse, working in collaboration with treating doctors, assists the patient and their family to reflect on the patient's goals, values and beliefs, help them to consider how they would like treatment decisions to be made if they became unable to do this for themselves, and to discuss and document any specific preferences.

This ACP facilitator supports patients to formally appoint a substitute decision maker, and document their preferences in an advance care directive (ACD) if they wish. If ACDs are completed, they are stored in the medical record in the legal section, and an electronic alert is placed on the hospital system.

\section{Participants}

All adults (aged 18 years or over) with stage $4-5 \mathrm{CKD}$, or on dialysis (CKD Stage 5D) or had a kidney transplant (CKD Stage 5T), who had died by December 2012 and had been referred to the ACP programs since its inception in March 2010, were included in the analysis. Historical control participants were adults (aged 18 years or over) with stage 4 - 5 CKD, on dialysis (CKD Stage 5D) or had a kidney transplant (CKD Stage 5T), who had died between January 2007 and December 2009. Controls were selected from the same renal unit and matched on age and gender to cases.

\section{Primary outcome variable}

This article is protected by copyright. All rights reserved. 
For each case patient and control, we examined (1) evidence of treatment received at end-oflife; (2) evidence that the patient's preferences for end-of-life care were known by the treating doctor, and the substitute decision maker; (3) evidence the medical team respected the patients' end-of-life preferences. Thus, the primary outcome variable was the proportion of patients where preferences were known (by substitute decision maker and/or clinicians) and adhered to by their treating doctors.

\section{Data sources and measurement}

For each case patient and control, demographic data, evidence of formal ACP, the presence of advance care directives and treatments received at end-of-life was collected from the medical records.

For cases only, administrative and conversation time spent during ACP was collected from the Advance Care Planning Department's clinical database. Additional cost data regarding the ACP intervention was provided by $(\mathrm{KD})$ the Medical Director of the Advance Care Planning Department at Austin Health. Health system resources involved in the last 12months of life was provided by the Clinical Costing department at Austin Health under the area codes defined by Common Chart of Accounts of Australian Treasury. ${ }^{11}$ We were unable to collect the hospital resource use in the last 12-months of life for controls as this same information was not collected prior to 2010 .

\section{Efforts to reduce bias}

This article is protected by copyright. All rights reserved. 
To reduce bias in rating the primary outcome variables, two members of the ACP department (KD \& WS) with medical training reviewed and coded case patient and control medical records independently and then compared findings. When there was disagreement between the two reviewers, discussion occurred until consensus was reached. In the event of patient records being unavailable due to death occurring outside the Austin hospital, the treating doctor for the patient was contacted and asked to provide this information.

Moreover, twenty-percent of the sample were randomly selected and coded by the renal unit director (DP) and reliability analysis was undertaken between first round of coding (WS and KD) and the coding by DP for the primary outcome variables. Both a percentage agreement and a kappa statistic were calculated.

\section{Statistical methods}

Chi square analyses were completed to examine differences between cases and controls and sample demographics, presence of ACP documentation, treatment outcomes (such as withdrawal of dialysis and palliative care referrals), preferences known by the substitute caregiver and treating doctor and whether preferences were adhered to at end-of-life.

\section{Health system resource use and costs}

This article is protected by copyright. All rights reserved. 
For each case patient, we present mean volume of resources use by category and mean costs per patient. All costs are reported in 2015 Australian dollars. Costs collected in years 20092014 were indexed to the most recent reference year using health-specific deflators. ${ }^{12} \mathrm{We}$ also present outcome data regarding resource use and costs based on cause of death (withdrawal from dialysis vs. other causes), including costs of care in the last 12 months of life, mean number of ICU admissions, mean number of nursing consultations and mean number of years between initiation of dialysis and death (Supplementary Table 2).

\section{Results}

Descriptive data

The study population included 57 cases and 57 controls. Cases and controls were matched by age and gender and there was no significant difference between cases and controls with respect to location of death and all were receiving dialysis therapy prior to death (Table 1). Age and gender distributions (i.e. $60 \%$ males, $40 \%$ females) are similar to the national average for patients aged 65-74 years who died between 2007-2012 as reported in the 2013 Australian and New Zealand Dialysis and Transplant Association Registry. ${ }^{13}$ Cases and controls represented 114 out of 361 deaths for ESKD patients at the hospital during the study time period $(32 \%)$.

\section{Primary outcomes}

This article is protected by copyright. All rights reserved. 
ACP data and end-of-life treatment outcomes (such as dialysis withdrawal and palliative care received) was collected for all 57 controls and 57 cases.

For the primary outcome variables, percentage of agreement between the first and second round of coding ranged between $88-92 \%$ respectively and kappa statistic level of agreement was high for all variables, ranging from 0.75 to 0.91 (Supplementary table 1).

\section{Primary outcome measure}

The main results of the study are presented in Table 2 . Cases were significantly more likely than controls to have their preferences known by both the substitute decision maker and the treating doctor and to have their preferences adhered to at end-of-life $(p<.001$, table 2$)$. Cases whose preferences were known by either the doctor or the substitute decision maker but not adhered to at end-of-life $(\mathrm{n}=15)$ were due to the following reasons: person died suddenly $(n=6)$, person's preferences not documented or available $(n=3)$, person's preferences documented but doctors were unaware of documents $(n=3)$, doctors aware of person's preferences but disagreed with them $(n=2)$ and unknown $(n=1)$.

\section{Secondary outcome measures}

ACP documentation

This article is protected by copyright. All rights reserved. 
Of the three types of ACP documents used at the hospital, cases completed significantly more documents compared to controls ( $\mathrm{p}<.05$, table 2$)$, with $38(67 \%)$ cases completing at least one type of ACP document compared to $6(11 \%)$ controls who had completed any ACP documents.

\section{End-of-life outcomes}

Cases were significantly more likely to withdraw from dialysis than controls overall and, of those who did withdraw from dialysis, cases were significantly more likely to withdraw from dialysis in accordance with their preferences (see Table 2). However, there was no statistical difference between cases and controls on whether palliative care was received at end-of-life. Of those patients who did withdraw from dialysis, the mean number of days between dialysis withdrawal and death was 3.03 (range from 0 to 12) for cases and 3.21 (range 0 to 15) for controls.

\section{Health system resources involved in the dedicated nurse-led ACP service}

Of the 57 cases referred to the ACP program in 2010/11, $52(91 \%)$ received the ACP intervention and the mean number of hours for the ACP consultation was 1.7 hours per patient. Taken together, the average cost of implementing the ACP intervention, including program setup, consultation and incidental costs, was $\$ 516$ per patient. Incidental costs were the greatest associated with the ACP intervention (63.5\%) and there was no additional time 
spent with ACP completers $(\mathrm{n}=52)$ versus ACP non-completers $(\mathrm{n}=5)$ for ACP consultation (Table 3a).

Hospital resource use and costs for cases

In the last 12 months of life, $54 \%$ of costs were related to nursing care, occurring mainly during dialysis treatment sessions and hospital admissions, costing $\$ 53,708(\mathrm{SD}=\$ 41,009)$ on average per patient, with the mean total cost of care $\$ 99,077(\mathrm{SD}=\$ 71,002)$ per patient (Table $3 b)$. Of the 14 patients who were admitted to ICU, 8 were admitted in accordance with their ACP preferences, 2 against their ACP preferences and 4 had not made their ACP preferences known. Overall, the average cost of providing the ACP intervention to cases equated to $0.5 \%$ of the hospital costs during the last 12 months of life.

This article is protected by copyright. All rights reserved. 


\section{Discussion}

This retrospective, case-controlled study shows that a coordinated approach to ACP facilitated by a trained dialysis nurse, working in collaboration with treating doctors, improves end-of-life care in ESKD by enabling patient's preferences to be articulated, documented, and respected at end-of-life. In this study, 84\% (38/47) of cases where preferences were known by the doctor were adhered to. Furthermore, our descriptive analysis of the health system resources involved in a dedicated nurse-led ACP service in ESKD, shows that the average cost of providing ACP per-patient was equal to $0.5 \%$ of the average hospital costs per-patient in the last 12-months of life.

These findings add to past studies of ACP in CKD examining caregiver preparedness for endof-life decision-making. Three randomized controlled trials $\mathrm{s}^{6,7,14,15}$ have demonstrated enhanced patient caregiver congruence compared to baseline on hypothetical goals of care questionnaires following a facilitated ACP intervention. However, two studies ${ }^{6,7}$ reported diminished concordance in patient-caregiver dyads over time and only one study measured end-of-life outcomes, ${ }^{8}$ showing a non-significant trend towards greater adherence to treatment preferences following ACP.

Past systematic reviews of treatment decision making in $\mathrm{CKD}^{16,17}$ show that some patients are uncertain about making decisions regarding the initiation and discontinuation of dialysis treatment and that may continue with dialysis only to maintain the status quo regardless of 
their initial preferences. Our case-control study demonstrates a significant improvement in CKD patient's preferences being known and adhered to at end-of-life following ACP compared to controls. Consistent with the study by Kirchoff et al. (2012), we found that significantly more patients who had participated in ACP withdrew from dialysis compared to controls, which we believe reflects greater patient and caregiver decisional empowerment following ACP. For example, of those who did withdraw from dialysis, cases were significantly more likely to withdraw in accordance with their preferences and recent qualitative research shows that ACP compels some people with ESKD and caregivers to change their beliefs and expectations about dialysis, such as by informing patients that they can withdraw from dialysis "on their own terms" in future circumstances in which they would no longer want dialysis to prolong their life. ${ }^{18}$

Moreover, to our knowledge, this is the first costing study of a nurse-led ACP service for people with CKD and one of few studies estimating costs of care in the last 12 months of life in a hospital for people with CKD. Evidence for the cost-effectiveness of ACP will facilitate appropriate resources planning and development of ACP models across finite health care resources. ${ }^{9}$ Whilst we have not presented a cost-effectiveness study in its entirety, we have provided important components of the overall health system resources involved in caring for people with ESKD in a hospital at end-of-life and implementing a nurse-led ACP program, for which there is currently very little data available. Thus, the data we have presented has the potential to inform future economic evaluations of ACP in CKD. 
Overall, we found incidental costs (recruiting and scheduling patients, commuting to meetings and consultation with renal clinicians) were the greatest costs associated with implementing ACP in ESKD. This finding is consistent with prior qualitative research, ${ }^{18,19}$ which suggests systematic efforts are required to improve interdisciplinary collaboration among renal clinicians to reduce conflict arising from ACP and increase ACP's overall effectiveness. Thus, improved ACP referral systems and renal clinician knowledge and buyin of ACP may have reduced overall incidental costs in the current study and allowed greater time to schedule and conduct ACP conversations with patients.

Although we found more cases received care at end-of-life in accordance with their preferences; there was no statistical difference between the number of cases and controls who died in hospital (70\% cases and 72\% controls) or received palliative care (32\% cases and $35 \%$ controls). This is similar to trends reported internationally ${ }^{20}$ and in Australia, with $66 \%$ of ESKD patients managed with dialysis in Australia estimated to die in hospital and 35\% to receive palliative care. ${ }^{1}$

In addition, 15 cases received medical treatment that was inconsistent with their known preferences at end-of-life for reasons including: i) the person's preferences were not documented or available; ii) the person's preferences were documented but the doctors were not aware of the documents or iii) because the doctors disagreed with the person's preferences. These findings are consistent with previously identified systemic barriers to ACP in nephrology ${ }^{18,19}$ and reinforce the importance of a collaborative approach between 
clinicians who facilitate ACP conversations and other clinicians in the renal unit and increased training, support, and awareness of ACP for nephrologists to support decisions that align with the patients' preferences. Furthermore, although we found no instances of caregivers overruling the patient's preferences at end-of-life in this study; a recent qualitative study suggests that caregivers may experience difficulty overcoming personal and decisional conflict adhering to the CKD patient's ACP preferences at end-of-life ${ }^{21}$ and require additional support in this regard.

In our study, two people with medical training rated the primary outcome variables and achieved agreement with an independent third rater who was a nephrologist. In addition, we inflated all health system costs to the most recent reference year for analysis. However, we acknowledge some limitations to generalizing these findings. Firstly, this was a retrospective single centre study conducted in Australia and thus reviewers were not blinded to the outcome measures. Because deaths of historical controls were up to 2 years prior to the deaths of cases it is possible that these findings reflect changes in clinical practice over time rather than the effect of the intervention. In addition, we were unable to access health system resource use and costs for controls in the last 12 months of life due to a change in the hospital's financial database and reporting system. Thus, we were unable to present a comparative cost analysis. Lastly, we did not conduct a prospective randomised controlled trial. To minimize any potential impacts the ACP intervention may have had within the renal units and patient outcomes, we chose to conduct a retrospective case control study instead and selected controls historically, before the ACP program existed. 
In conclusion, ACP was associated with improved knowledge of ESKD patient's preferences and adherence to those preferences at end-of-life. In addition, we present the health system resource use and costs involved in a dedicated nurse-led ACP service in ESKD and the health system resources accrued in a hospital in the last 12-months of life in ESKD. These findings may be useful in informing further research and clinical service development in ACP for people with CKD. Senior nurses may be appropriate to facilitate ACP in people with $\mathrm{CKD}$, following appropriate training and with ongoing medical supervision. Future trials of ACP may systematically address interdisciplinary collaboration between renal clinicians and ACP facilitators to reduce incidental costs and to increase ACP effectiveness in improving patient and caregiver outcomes.

\section{Acknowledgements}

We thank Ms Diane Chaffers for her role in facilitating advance care planning with patients and caregivers during the period of the study.

MS is supported by a University of Sydney Postgraduate Award and the Ramsay Health Care Foundation Top-Up Scholarship. RM is supported by an Australian National Health and Medical Research Council Fellowship (1054216). AT is supported by a National Health and Medical Research Council Fellowship (1106716). The funders had no role in study design; collection, analysis, and interpretation of data; writing the report; or the decision to submit the report for publication. The authors declare no conflict of interests exists.

This article is protected by copyright. All rights reserved. 


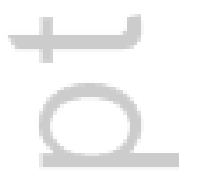

This article is protected by copyright. All rights reserved. 


\section{References}

1. Morton RL, Webster AC, McGeechan K, et al. Conservative Management and End of Life Care in an Australian Cohort with ESRD. Clin J Am Soc Nephrol. 2016; 11: 2195-203.

2. Feely MA, Hildebrandt D, Varayil JE and Mueller PS. Prevalence and contents of advance directives of patients with ESRD receiving dialysis. Clin J Am Soc Nephrol. 2016; 12: 2204-9.

3. Weisbord S, Carmody S, Bruns F, et al. Symptom burden, quality of life, advance care planning and the potential value of palliative care in severely ill haemodialysis patients. NDT. 2003; 18: 1345-52.

4. Swartz RD and Perry E. Advance directives are associated with "good deaths" in chronic dialysis patients. J Am Soc Nephrol. 1993; 3: 1623-30.

5. Tamura MK, Montez-Rath ME, Hall YN, Katz R and O'Hare AM. Advance Directives and End-of-Life Care among Nursing Home Residents Receiving Maintenance Dialysis. Clin J Am Soc Nephrol. 2017; 12: 435-42.

6. Song M-K, Ward SE, Fine JP, et al. Advance care planning and end-of-life decision making in dialysis: a randomized controlled trial targeting patients and their surrogates. $\mathrm{Am} J$ Kidney Dis. 2015; 66: 813-22.

7. Song MK, Ward SE, Happ MB, et al. Randomized controlled trial of SPIRIT: An effective approach to preparing African-American dialysis patients and families for end of life. Res Nurs Health. 2009; 32: 260-73.

8. Kirchhoff KT, Hammes BJ, Kehl KA, Briggs LA and Brown RL. Effect of a diseasespecific advance care planning intervention on end-of-life care. Journal of the American Geriatrics Society. 2012; 60: 946-50.

9. Morton RL, Tamura MK, Coast J and Davison SN. Supportive care: Economic considerations in advanced kidney disease. CJASN. 2016: CJN. 12651115.

10. Von Elm E, Altman DG, Egger M, et al. The Strengthening the Reporting of Observational Studies in Epidemiology (STROBE) Statement: guidelines for reporting observational studies. Int J Surg. 2014; 12: 1495-9.

11. Independent Hospital Pricing Authority (AUS). Hospital Patient Costing Standards [Internet]. Australian Hospital Patient Costing Standards - Version 3.1 - July 2014; [cited 2017 Nov 09]. Available from:

https://www.ihpa.gov.au/sites/g/files/net636/f/publications/ahpcs-version3.1.pdf

12. Australian Institute of Health and Welfare. Health expenditure Australia 2014-15 [Internet]. Health and welfare expenditure series no. 57. Cat. no. HWE 67. Canberra: AIHW; [cited 2017 Nov 09]. Available from: https://www.aihw.gov.au/getmedia/a13427b8-d5de495d-8b8f-4fd114f135d0/20279.pdf.aspx?inline=true.

13. McDonald S. Deaths. ANZDATA Registry Report 2013. [Internet] Australia and New Zealand Dialysis and Transplant Registry Adelaide, South Australia. [updated 2014; cited 2017 Dec 20]. Available from:

http://www.anzdata.org.au/anzdata/AnzdataReport/36thReport/ANZDATA_36th_Annual_Re port.pdf. 
14. Song M-K, Donovan HS, Piraino BM, et al. Effects of an intervention to improve communication about end-of-life care among African Americans with chronic kidney disease. Appl Nurs Res. 2010; 23: 65-72.

15. Kirchhoff KT, Hammes BJ, Kehl KA, Briggs LA and Brown RL. Effect of a diseasespecific planning intervention on surrogate understanding of patient goals for future medical treatment. Journal of the American Geriatrics Society. 2010; 58: 1233-40.

16. Morton R, Tong A, Howard K, Snelling P and Webster A. The views of patients and carers in treatment decision making for chronic kidney disease: systematic review and thematic synthesis of qualitative studies. BmJ. 2010; 340: c112.

17. Tong A, Cheung KL, Nair SS, et al. Thematic synthesis of qualitative studies on patient and caregiver perspectives on end-of-life care in CKD. American Journal of Kidney Diseases. 2014; 63: 913-27.

18. Sellars M, Tong A, Luckett T, et al. Clinicians' Perspectives on Advance Care Planning for Patients With CKD in Australia: An Interview Study. Am J Kidney Dis. 2017; 70: $315-23$.

19. O'Hare AM, Szarka J, McFarland LV, et al. Provider perspectives on advance care planning for patients with kidney disease: Whose job is it anyway? CJASN. 2016; 11: 855-66. 20. Murray AM, Arko C, Chen S-C, Gilbertson DT and Moss AH. Use of hospice in the United States dialysis population. CJASN. 2006; 1: 1248-55.

21. Sellars M, Clayton JM, Morton RL, et al. An Interview Study of Patient and Caregiver Perspectives on Advance Care Planning in ESRD. American Journal of Kidney Diseases. 2017. 
Table 1. Patient characteristics (cases and controls).

Variable Controls n (\%)

Cases n (\%)

\begin{tabular}{lcc}
\hline Gender & $38(67)$ & $38(67)$ \\
\multicolumn{1}{c}{ Males } & $19(33)$ & $19(33)$ \\
$\quad$ Females & $73.78(37,90)$ & $74.04(44,92)$ \\
Mean age in years (range) & $4.37(0.01,15)$ & $5.28(0.1,17)$ \\
Mean number of years spent & & \\
on dialysis (range) & & $40(70)$ \\
Location of death & $41(72)$ & $17(30)$ \\
$\quad$ Hospital & $16(28)$ & \\
$\quad$ External $\dagger$ &
\end{tabular}

This article is protected by copyright. All rights reserved. 
Table 2. Comparison of completion of ACP documentation and end-of-life care and treatment outcomes between cases $(n=57)$ and controls $(n=57)$.

\begin{tabular}{|c|c|c|c|c|}
\hline Outcome & $\begin{array}{l}\text { Controls } \\
n(\%)\end{array}$ & $\begin{array}{l}\text { Cases } \\
n(\%)\end{array}$ & $C^{2}$ & $P^{\dagger}$ \\
\hline \multicolumn{5}{|l|}{ Completion of ACP documentation } \\
\hline $\begin{array}{l}\text { Legally appointed substitute decision } \\
\text { maker }\end{array}$ & $3(5.2)$ & $39(67.2)$ & 48.37 & $<.001$ \\
\hline Common-law advance care directive & $6(10.3)$ & $27(46.6)$ & 18.68 & $<.001$ \\
\hline Legislative advance care directive & $1(1.7)$ & $10(17.2)$ & 8.14 & .01 \\
\hline \multicolumn{5}{|l|}{ Knowledge of and adherence to $A C P$} \\
\hline \multicolumn{5}{|l|}{ preferences } \\
\hline $\begin{array}{l}\text { Preferences known by substitute } \\
\text { decision maker }\end{array}$ & $15(26.3)$ & $52(89.7)$ & 47.43 & $<.001$ \\
\hline Preferences known by treating doctor & $23(40.4)$ & $47(82.4)$ & 19.20 & $<.001$ \\
\hline Preferences adhered to at end-of-life & $15(26.8)$ & $38(66.7)$ & 18.04 & $<.001$ \\
\hline \multicolumn{5}{|l|}{ Treatment decisions at end-of-life } \\
\hline Withdrawal from dialysis & $33(58)$ & $40(70)$ & 7.6 & .02 \\
\hline Dialysis withdrawn in accordance & $11(33)$ & $33(83)$ & 16.08 & $<.001$ \\
\hline with ACP preferences & & & & \\
\hline Received palliative care & $20(35)$ & $18(32)$ & 0.2 & .84 \\
\hline
\end{tabular}

This article is protected by copyright. All rights reserved. 
Table 3a. Healthcare utilisation and costs of a nurse-led advance care planning intervention among adults with end-stage kidney disease managed on dialysis (2010-2011)

\begin{tabular}{|c|c|c|c|c|c|c|c|c|}
\hline \multirow[t]{2}{*}{ Healthcare resources } & \multicolumn{3}{|c|}{$\begin{array}{c}\text { Intervention group all } \\
\text { including non-completers } \uparrow \text {, } \\
\mathrm{n}=57\end{array}$} & \multicolumn{3}{|c|}{$\begin{array}{c}\text { Intervention group } \\
\text { completers } \uparrow \dagger \text { only, } \mathrm{n}=52\end{array}$} & \multicolumn{2}{|c|}{ Total costs } \\
\hline & $n$ (hours) & $\begin{array}{l}\text { Mean per } \\
\text { patient } \\
\text { (hours) }\end{array}$ & SD & $n$ (hours) & $\begin{array}{l}\text { Mean per } \\
\text { patient } \\
\text { (hours) }\end{array}$ & SD & $\begin{array}{l}\text { Costs } \\
\text { (AUD) }\end{array}$ & $\%$ \\
\hline $\begin{array}{l}\text { Set up program costs } \\
\text { 2-day training workshop, including } 1 \text { day of on-line learning; and } 1 \\
\text { day of face-to-face workshop with an experienced ACP clinician } \ddagger \\
\text { (calculated as } 16 \text { hours for trainee and } 8 \text { hours for trainer at hourly rate } \\
\text { for ACP clinician)§ }\end{array}$ & - & - & - & - & - & - & $\$ 1,089$ & 4.1 \\
\hline $\begin{array}{l}8 \text { supervised ACP conversations with experienced ACP clinician } \\
\text { (calculated as } 1.7 \text { hours per conversation times } 8 \text { conversations at } \\
\text { hourly rate for } 2 \mathrm{ACP} \text { clinicians) }\end{array}$ & - & - & - & - & - & - & $\$ 1,235$ & 4.6 \\
\hline $\begin{array}{l}\text { Senior medical supervision } \Phi \text { (calculated as a percentage of total } \\
\text { patients seen within the department versus total number of cases } \\
\text { included at } 8 \text { hours per fortnight for the duration of the study) }\end{array}$ & - & - & - & - & - & - & $\$ 3,669$ & 13.7 \\
\hline ACP consultation costs & & & & & & & & \\
\hline Conversation time with patient / caregivers & 50.7 & 0.9 & 1.0 & 50.7 & 1.0 & 1.1 & $\$ 2,299$ & 8.6 \\
\hline $\begin{array}{l}\text { Administration time to sign and file documents and update patient } \\
\text { records } \\
\text { Incidental costs }\end{array}$ & 35.0 & 0.6 & 0.6 & 35.0 & 0.7 & 0.6 & $\$ 1,589$ & 5.9 \\
\hline
\end{tabular}


Recruitment and scheduling of patients, commuting to meetings and consultation with renal clinicians (calculated as a percentage of total patients seen by the ACP clinician versus total number of cases

included at 16 hours per fortnight for the duration of the study minus

costs incurred for ACP conversations and administration time)

$$
\text { Total }
$$

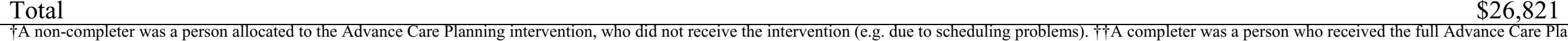
intervention.

§Excluding in-kind costs from the hospital (such as venue hire and catering)

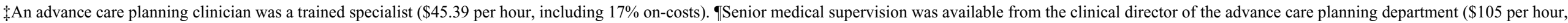
including $17 \%$ on-costs)

Abbreviations: ACP, advance care planning 
Table 3b. Healthcare utilisation and costs of a nurse-led Advance Care Planning intervention among adults with end-stage kidney disease managed on dialysis - last 12 months of life $(\mathrm{n}=57)$

\begin{tabular}{|c|c|c|c|c|c|c|}
\hline \multirow[t]{2}{*}{ Hospital resources } & \multirow[b]{2}{*}{$\begin{array}{c}n \\
\text { patients }\end{array}$} & \multicolumn{3}{|c|}{ Number of units per patient } & \multicolumn{2}{|c|}{ Total costs } \\
\hline & & Mean & $\mathrm{SD}$ & Range & Costs & Percentage \\
\hline $\begin{array}{l}\text { Allied health visits, including } \\
\text { dietician and nutritionist, } \\
\text { occupational therapist, orthotics, } \\
\text { physiotherapy, social work and } \\
\text { speech therapy }\end{array}$ & 55 & 127.4 & 242.3 & $0^{\dagger}$ to 1195 visits per patient & $\$ 183,967$ & $3.3 \%$ \\
\hline Emergency department visits & 49 & 5.4 & 4.9 & $0^{\ddagger}$ to 18 visits per patient & $\$ 124,418$ & $2.2 \%$ \\
\hline Intensive care unit admissions & 14 & 0.4 & 0.8 & $\begin{array}{l}0^{\S} \text { to } 4 \text { admissions per } \\
\text { patient }\end{array}$ & $\$ 197,047$ & $3.5 \%$ \\
\hline Imaging procedures & 56 & 8.3 & 6.6 & $\begin{array}{l}0^{\text {f }} \text { to } 28 \text { procedures per } \\
\text { patient }\end{array}$ & $\$ 300,385$ & $5.3 \%$ \\
\hline $\begin{array}{l}\text { Nursing, scheduled consultations } \\
\text { by a registered nurse or nurse } \\
\text { practitioner, such as dialysis }\end{array}$ & 57 & 186.0 & 227.9 & $\begin{array}{l}1 \text { to } 1195 \text { consultations per } \\
\text { patient }\end{array}$ & $\$ 3,061,360$ & $54.2 \%$ \\
\hline Pathology tests & 57 & 120.2 & 194.1 & 1 to 1047 tests per patient & $\$ 213,996$ & $3.8 \%$ \\
\hline $\begin{array}{l}\text { Pharmacy, including the purchase, } \\
\text { production, distribution, supply } \\
\text { and storage of drug products and } \\
\text { clinical pharmacy services }\end{array}$ & 55 & 25.4 & 33.3 & $\begin{array}{l}0^{\dagger \dagger} \text { to } 202 \text { scripts / meds per } \\
\text { patient }\end{array}$ & $\$ 378,358$ & $6.7 \%$ \\
\hline $\begin{array}{l}\text { Surgery, including operating } \\
\text { theatre and surgeon costs }\end{array}$ & 53 & 57.7 & 72.3 & $\begin{array}{l}0 \text { to } 203 \text { operations per } \\
\text { patient }\end{array}$ & $\$ 361,681$ & $6.4 \%$ \\
\hline
\end{tabular}




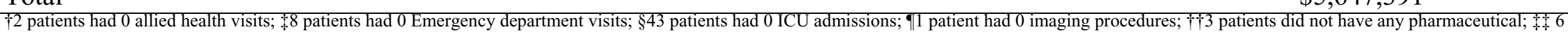
patients had 0 operations.

$\S \S$ mean cost per patient $=\$ 99,077(\mathrm{SD}=\$ 71002)$ 


\section{University Library}

\section{- M I I N E R VA \\ A gateway to Melbourne's research publications}

Minerva Access is the Institutional Repository of The University of Melbourne

Author/s:

Sellars, M;Morton, RL;Clayton, JM;Tong, A;Mawren, D;Silvester, W;Power, D;Ma, R;Detering, KM

Title:

Case-control study of end-of-life treatment preferences and costs following advance care planning for adults with end-stage kidney disease

Date:

2019-02-01

Citation:

Sellars, M., Morton, R. L., Clayton, J. M., Tong, A., Mawren, D., Silvester, W., Power, D., Ma, R. \& Detering, K. M. (2019). Case-control study of end-of-life treatment preferences and costs following advance care planning for adults with end-stage kidney disease. NEPHROLOGY, 24 (2), pp.148-154. https://doi.org/10.1111/nep.13230.

Persistent Link:

http://hdl.handle.net/11343/285383 